\title{
História oral e produção de conhecimentos com seringueiros do município de Xapuri no estado do Acre (1988-2012)
}

\author{
Carlos Estevão Ferreira Castelo* \\ ORCID iD 0000-0002-4694-9639 \\ Universidade Federal do Acre, Centro de Ciências Jurídicas Sociais Aplicadas, Rio Branco, Brasil
}

\begin{abstract}
Resumo: No presente artigo procurou-se compreender as principais mudanças nos modos de viver dos seringueiros de Xapuri, no estado do Acre, no período de 1988 a 2012, sob a ótica da experiência vivida e narrada pelos próprios sujeitos da ação histórica. A ideia básica foi produzir conhecimentos de forma partilhada com os residentes da área pesquisada. Para isso, foram utilizadas estratégias metodológicas de história oral. A possibilidade do desaparecimento dos seringueiros enquanto categoria social, deixando o território limpo para uma provável exploração dos recursos naturais em um futuro não muito distante, constitui-se uma das principais conclusôes. $\mathrm{O}$ artigo problematiza também as percepçóes dos seringueiros com relação ao manejo madeireiro, realizado em áreas de florestas protegidas, além de mudanças em seus modos de vida.
\end{abstract}

Palavras-chave: História Oral. Seringueiros. Acre.

Oral history and the production of knowledge with rubber tappers in the town of Xapuri, state of Acre (1988-2012)

Abstract: The purpose of this paper is to understand the main changes that occurred between 1988 and 2012 in the ways rubber tappers lived in Xapuri, state of Acre. These changes were analyzed through the experience lived and narrated by the subjects of the historical action themselves. The basic idea was to produce knowledge in collaboration with the residents of the area studied. In order to achieve such purpose, we used methodological strategies of oral history. One of our main findings is that the rubber tappers as a social category may disappear, which will leave the territory available for its natural resources

Doutor em História Social pela Universidade de São Paulo (USP). Professor Associado 4 do Centro de Ciências Jurídicas e Sociais Aplicadas da Universidade Federal do Acre (CCJSA/UFAC). Professor dos Programas de Pós-Graduação de Geografia e História da UFAC. E-mail: carlos.castelo@ufac.br. 
to be exploited in the not too distant future. Besides examining the changes in the way rubber tappers lived, this paper also problematizes their perceptions of timber management in forest protection areas.

Keywords: Oral history. Rubber tappers. Acre.

\section{Introdução}

No presente artigo, procura-se compreender as principais mudanças nos modos de viver dos seringueiros de Xapuri no estado do Acre no período de 1988 a 2012, sob a ótica da experiência vivida e narrada pelos próprios sujeitos da ação histórica (produção partilhada de conhecimentos). Para tanto, optou-se pela utilização de estratégias metodológicas da história oral.

É importante dizer que a referência no texto feita ao termo seringueiro, ou seringueiros, trata-se dos sujeitos que vivem ainda hoje nas florestas do estado do Acre, e em outras regiôes da Amazônia, praticando a extração do látex de seringueiras (Hevea brasiliensis), coletando castanha (Bertholletia excelsa H.B.K), criando pequenos animais para autoconsumo e, também, praticando agricultura/pecuária de pequena dimensão. No tempo presente, na luta pela sobrevivência, todas essas tarefas podem ser realizadas por uma única pessoa, diferentemente do que acontecia com o seringueiro do primeiro "ciclo da borracha" (1879-1912), que se dedicava exclusivamente à produção de borracha.

$\mathrm{O}$ uso da expressão seringueiro foi feita não com a ideia de classificar e ou normalizar, até porque o sujeito é proteiforme (assume identidades). Na floresta, durante a pesquisa de campo, dialogou-se com o sujeito que corta seringa; com o sujeito que corta seringa e recebe Bolsa Família; com aqueles que possuem plantio "de roçado"; que são pais; que traem a esposa; que jogam dominó; que fazem "bico" vendendo sua força de trabalho a terceiros; que vão à igreja; que não votam em candidato $\mathrm{A}$ ou $\mathrm{B}$; que jogam futebol. Inclusive, alguns que fazem questão de dizer que são seringueiros, mas não trabalham mais cortando seringa. Também sujeitos que podem matar o próximo quando são ofendidos, mas que se dizem defensores da floresta. Portanto, não considerá-los como seringueiros significaria negar as historicidades de suas vidas.

Isso posto, informa-se que o artigo foi seccionado nos seguintes subitens, além da introdução: 1) informaçóes sobre conjunturas, limites e pressôes que determinaram as condiçóes de vida e de trabalho dos seringueiros de Xapuri (AC); 2) detalhamento do trabalho de pesquisa realizado com o aporte metodológico da história oral; e 3) consideraçóes finais, nas quais são apontados alguns dos resultados da pesquisa desenvolvida. 


\section{Conjunturas, limites e pressões que determinaram as condições de vida e de trabalho dos seringueiros de Xapuri (AC)}

Foi durante o domínio da empresa extrativista na Amazônia (1879-1912) que os ancestrais dos sujeitos da pesquisa se tornaram seringueiros - base fundamental de exploração estruturada nas relaçôes mercantis. Nesse tempo histórico, o tipo de exploração baseava-se em um sistema de organização da produçáo ("aviamento"), que gerava riquezas e fazia crescer a produçáo de borracha em toda regiáo Amazônica. Sobre o "sistema de aviamento", Martins (1994, p. 10) nos informa que:

[...] se tornou não só um regime de exploraçáo do trabalho, mas também um sistema de dominação política e de manifestação do poder pessoal. $\mathrm{Na}$ verdade, ele passou a regular inteiramente as relaçóes sociais dos trabalhadores dos seringais, do trabalho à festa. Ele se firmou como um modelo de relacionamento entre o trabalhador e o patrão derivado da dominaçáo de tipo patrimonial. No aviamento, o núcleo da relaçáo de trabalho parece se constituir em variaçóes de um duplo sistema de crédito sem dinheiro, bancário e comercial, em que os juros são cobrados extorsivamente ao longo da cadeia de financiamentos que vai da casa exportadora de borracha ao trabalhador do seringal $[\ldots]$.

A partir do desenvolvimento da produçáo de borracha racional na Malásia, a economia gomífera na Amazônia Brasileira é fortemente prejudicada. Em crise, a atividade extrativista de borracha declinava sensivelmente, só voltando a apresentar sinais de recuperaçáo durante a Segunda Guerra Mundial, no período designado pela historiografia regional como "Batalha da Borracha" (Martinello, 1988). Com o final da guerra novamente a crise se estabelece, levando o extrativismo gomífero praticado na regiáo a uma estagnaçáo quase completa (por volta de 1950/1960, os seringais estavam totalmente decadentes).

No caso do Acre, muitos seringueiros que viviam nas florestas começaram a migrar para as cidades. Outros, talvez antevendo dificuldades que teriam efetivando a saída das matas, decidem continuar na floresta buscando a sobrevivência que era possível.

Com a chegada da frente pioneira pecuarista ${ }^{1}$ nos anos da década de 1970, incentivada pelas iniciativas modernizadoras dos fardados, o cenário acreano começa a sofrer mudanças significativas. A existência dos seringueiros como categoria social fica bastante ameaçada, forçando-os a buscarem novas formas de resistir. Se antes a resistência se dava de forma individual e autônoma, passou a ser de forma predominantemente coletiva.

Durante esse período muitas famílias são mortas e/ou expulsas do território por produtores sulistas (precisavam limpar a terra para implantação da pecuária e/ou

Sobre o conceito de "frente pioneira", verificar em Martins (1996). 
especular com a terra). Os seringueiros que decidem resistir passam a fazer isso através da organização sindical e dos "empates", entre outras estratégias inventadas. Surgia no Acre o que ficou conhecido mundialmente como "movimento de resistência dos seringueiros", resistência contra a expropriação dos territórios.

Observa-se que os "empates" configuraram-se como uma das principais estratégias para impedir a derrubada da floresta e, dessa forma, preservar os modos de vida. Na linguagem local, "empate" era sinônimo de impedir. Da mesma maneira que os seringueiros empatavam as brigas e empatavam outros seringueiros de coletar látex em árvores de seringueiras que não pertenciam às suas "estradas de seringa", empatavam a derrubada e a queima da floresta pelos "novos donos". Através dessas manifestaçôes coletivas e solidárias, conseguiram impedir muitos fazendeiros de transformarem as florestas em pastos para seus bois. No meio das lutas travadas, uma liderança se destacou: Francisco Alves Mendes Filho, o Chico Mendes.

Em dezembro de 1988, Chico Mendes foi assassinado por fazendeiros na Cidade de Xapuri. Entretanto, as lutas lideradas por Mendes, junto com muitos outros seringueiros, haviam gerado frutos. Um dos mais importantes foi a criação de uma Reserva Extrativista (Resex). A Resex, para os seringueiros, constituía-se em uma proposta inovadora de reforma agrária.

Mesmo com essa importante conquista, a sobrevivência nas matas xapurienses nos primeiros dez anos após a morte do líder seringueiro Chico Mendes tornou-se bastante complicada, principalmente devido a fatores como a queda nos preços da borracha no mercado internacional. Dessa forma, novas transformaçôes, novas lutas, novas resistências e tentativas de construção de uma sobrevivência possível passaram a marcar o processo.

Mesmo com a criação da Resex, que garantia a posse da terra, muitos seringueiros continuaram migrando para as cidades acreanas e/ou para a Bolívia. Viram-se, também nesse tempo, famílias começando a substituir a produção tradicional extrativista (borracha e castanha) por usos mais intensivos da terra. Significativos aumentos da atividade pecuária e de desmatamentos também passaram a acontecer.

\section{A história oral como aporte metodológico para a produção de conhecimentos com seringueiros}

A pesquisa foi realizada no período de 2011 a 2014. Seu foco principal relacionouse com a busca da compreensão dos encontros e desencontros, avanços e recuos, vitórias e derrotas dos seringueiros de Xapuri (AC) após 1988, ano em que Chico Mendes foi assassinado.

A questáo principal tratou das possíveis mudanças nos modos de vida dos seringueiros. A ideia foi compreender as mudanças no modo de viver sob a ótica da 
experiência vivida e narrada pelos próprios sujeitos da ação histórica. Especificamente, procurou-se descobrir se os investimentos do Governo Estadual estavam ou não sendo fundamentais na mudança do cenário da vida do lugar, quais modificaçôes aconteciam nos processos produtivos e nas formas do uso da terra, se estaria ocorrendo concentração de terras pelo capital na regiáo e, ainda, se o território ocupado pelos seringueiros estaria passando por um processo de esvaziamento.

Esses e outros questionamentos direcionaram a pesquisa para a busca de explicaçôes não só sobre as mudanças em si (figura), como também (e principalmente) sobre coisas que poderiam estar por trás de outras (pano de fundo). Assim, optou-se pela metodologia da história oral como principal estratégia metodológica, com vistas a estabelecer o diálogo com as vozes dos seringueiros, bem como observar (e analisar) seus modos de vida. ${ }^{2}$

Entendida ora como técnica, ora como metodologia ou até disciplina, a História Oral é parte de um movimento de renovação da História que, no começo no século XX, ampliou seus objetos, fontes e passou a incorporar imagens, cultura material e relatos orais gravados em suas pesquisas, antes restritas aos documentos escritos. (Carvalho Mariano, 2020, p. 215).

Acreditava-se que o caminhar pela propositura da história oral, para Paul Thompson (1992) a primeira espécie de história, oportunizaria aos parceiros da pesquisa uma possibilidade de narrarem suas histórias, de darem seus testemunhos contando parte de suas vidas, numa construção narrativa que poderia trazer à tona recordaçóes e esquecimentos, presenças e ausências, consideradas vitais para a compreensão dos processos históricos.

Conforme nos ensina Meihy e Holanda (2007), as fontes orais são importantes na medida em que possibilitam abordagens que vão além das informaçóes filtradas por documentos oficiais e oficializados. Sendo assim, seria relevante reconhecer na história os seres humanos, e não tratar as situaçóes como se fossem movimentos institucionais.

Foram escolhidas as estratégicas metodológicas da história oral também por se conceber uma "possibilidade mediada de captar as experiências, uma vez que as pessoas não narram apenas sobre os fatos, mas também sobre suas interpretaçóes a respeito dos acontecimentos" (Fávero; Morais, 2020, p. 156). Experiências, no caso, dos seringueiros.

Concordando com Lima Júnior (2021, p. 68), concebe-se a história oral como um

[...] instrumento metodológico enriquecedor, pois vozes múltiplas se encontram socialmente, constituindo um campo de memórias diversificadas, cujo debate fortalece a experiência social de aprender aquilo que se desconhece por quem tem um tesouro: as recordaçóes.

Sobre o observar os modos de viver, Teresa Caldeira apud Albuquerque (2005) indica que o pesquisador deve entrar no cotidiano das pessoas. Sem os dados da observação e da vivência, não se consegue interpretar bem as entrevistas e, consequentemente, o que resulta desses relatos na vida das pessoas do lugar. 
Com o início das entrevistas, logo se percebe que as falas diretas dos seringueiros possibilitavam a captaçáo das diversas dimensões a respeito das representaçóes concernentes às suas resistências, aos seus modos de vida, as marcas de suas lutas.

A subjetividade encontrada nos relatos (colhidos através da modalidade histórias de vida) mostrou-se preciosa, principalmente porque deu conta mais sobre os significados do que sobre os eventos. Nas narrativas contadas encontraram-se não só fatos históricos, mas também esquecimentos, fantasias, sonhos, mentiras, etc. Em outras palavras, são narrativas que representaram uma versão - nem melhor nem pior - única de vivências filtradas pela experiência e pelo tempo, são relatos que não representaram a fidelidade do que se passou, de como se deram as coisas, mas constituíam-se em momentos narrativos, confirmando as afirmaçôes de Benjamin (1985) de que uma narrativa não estaria interessada em transmitir o "puro em si" da coisa narrada, como uma informação ou um relatório.

Sobre histórias de vida, vale assinalar o que Fabiana Moreira Lima e Henrique Salmazo da Silva destacaram:

Nessa modalidade, o narrador (ou seja, aquele que está compartilhando a sua história) apresenta maior liberdade para relatar suas experiências de vida; tal recurso permite ao pesquisador entender não apenas como a pessoa experiencia a sua vida como também seu processo de compreensão acerca dela. (Lima; Silva, 2021, p. 129).

Na visão de José Carlos Sebe Bom Meihy, em entrevista concedida para Carvalho Mariano (2020, p. 219) "a história oral de vida tem cunho evocativo dos fatos e momentos memoráveis de colaboradores que se dispóem a contar suas trajetórias a partir de diálogos pontuados por aspectos subjetivos e, neste caso, a entrevista deve ser aberta e dialógica na plenitude possível”.

\section{Detalhamento das estratégias de história oral utilizadas}

No mês de outubro de 2011, iniciaram-se as primeiras conversas informais com os seringueiros habitantes das florestas de Xapuri para convidá-los a pesquisar e, ainda, realizar os agendamentos das entrevistas, as chamadas "pré-entrevistas" (Meihy, 1996).

Nas "pré-entrevistas" foi possível explicar, em linhas gerais, as diretrizes programáticas de todo o projeto, bem como valorizar a experiência pessoal de cada seringueiro procurado. Não se observaram resistências. Talvez devido às cuidadosas explicaçóes sobre cada etapa planejada do trabalho (finalidade, agendamento, coleta, formas de devolução, etc.).

Nessas conversas iniciais, constatou-se que na regiáo existiam seringueiros com particularidades diferentes, ou seja, famílias que praticavam, além do extrativismo 
dito tradicional, ${ }^{3}$ outras atividades, como o manejo de madeira. Existiam também seringueiros que não aceitavam trabalhar com o manejo madeireiro, apenas extraiam látex e coletavam castanha-do-brasil (Bertholletia excelsa H.B.K), além de manterem um pequeno roçado, onde praticavam agricultura de pequena dimensão e realizavam criaçóes de pequenos animais. Verificou-se que existiam seringueiros mais politizados que outros, devido à participação no Sindicato de Trabalhadores Rurais de Xapuri (STTR de Xapuri), alguns com ligaçóes fortes com o Governo do Estado do Acre da época e, ainda, com diferentes padróes de vida (nesse caso, devido às formas e quantidade de ganhos). Essas constataçóes direcionaram para a criação de duas "redes" (Meihy, 1996a) de colaboradores.

Para Meihy, a colônia é definida "pelos padróes gerais de sua comunidade de destino", que é "aquilo que identifica as pessoas, os motivos, as trajetórias que as reúnem em características afins" (1996a, p. 53); já a rede, é "uma subdivisão da colônia e que visa estabelecer parâmetros para decidir sobre quem deve ser entrevistado ou não..." (1996a, p. 53).

Assim, para a coleta dos relatos orais, estabeleceu-se a "rede" 1 , formada por sujeitos residentes na regiáo da Reserva Extrativista Chico Mendes (Resex Chico Mendes), no Município de Xapuri (AC), e a "rede" 2, formada por seringueiros residentes em colocaçôes ${ }^{4}$ do antigo seringal Cachoeira, hoje Projeto de Assentamento Agroextrativista Cachoeira (PAE Cachoeira). Ressalte-se que na região da "rede" 1 não se praticava o manejo de madeira. Enquanto na "rede 2", acontecia essa prática, até com certa intensidade.

Observou-se que muitos seringueiros da regiáo da "rede" 2 haviam convivido com Chico Mendes nos "movimentos de resistência" contra a expansão da fronteira agrícola capitalista na Amazônia nos anos de 1970 e 1980. Há que se registrar que alguns familiares do líder seringueiro moravam na região. No PAE Cachoeira, detectou-se uma quantidade grande de famílias que possuíam relaçóes fortes e próximas com o Governo do Estado do Acre da época (alguns eram funcionários do Governo). Aqueles que trabalham com seringa (extração de látex) possuíam um único comprador do "leite" (látex): uma fábrica de preservativos, cujo nome era Natex. A unidade era administrada por uma organização governamental denominada Fundação de Tecnologia do Estado do Acre (Funtac).

Na região da "rede" 1, também constatou-se a presença forte do Estado (Governo

3 Rêgo, Costa Filho e Braga (1996) definem o extrativismo tradicional como a coleta de látex de seringueiras e castanha. O extrativismo renovado, ou "neoextrativismo", aconteceria com melhorias técnicas do extrativismo tradicional. Exemplos de "neoextrativismo": "couro ecológico", ilhas de alta produtividade de seringueiras, etc.

4 A colocação de seringa é um trecho dentro da floresta que um seringueiro ou uma família ocupa, onde ele constrói sua casa. Geralmente possui um pequeno roçado no qual cultiva produtos para o próprio consumo. Um seringal, no período áureo da exploração de borracha na Amazônia, era formado por várias colocações. 
do Acre) desde as primeiras conversas, mas náo em todas as colocaçóes. A presença do Governo Estadual era menos intensa em localidades mais distantes da cidade de Xapuri, principalmente nas áreas habitadas por famílias que não forneciam matériaprima para a Natex. O mesmo ocorria naquelas localidades onde a energia elétrica (programa Luz Para Todos) ainda não havia chegado.

A coleta dos relatos teve início em outubro de 2011, com dois seringueiros que se constituíram como entrevistas "ponto zero" (Meihy, 1996). Obteve-se o relato da seringueira Dercy Perez de Carvalho Cunha, na época Presidente do Sindicato dos Trabalhadores Rurais de Xapuri, e do seringueiro Luiz Targino de Oliveira, fundador dos sindicatos de trabalhadores rurais dos municípios de Xapuri e Brasiléia.

Nascido no Ceará, Targino narrou ter vindo para o Acre após a Segunda Guerra Mundial, no pós-período da "Batalha da Borracha". Observa-se que, na ocasião da entrevista, Targino estava aposentado como "soldado da borracha" e vivia na cidade de Xapuri. Informou que, de 1954 até o início dos anos de 1980, viveu valiosas experiências nos seringais acreanos, principalmente nos da regiáo do antigo seringal Cachoeira. Destacou ter lutado contra a expulsão dos seringueiros das florestas ao lado de Chico Mendes nas décadas de 1970 e 1980. Ressaltou também que, entre os participantes do "movimento de resistência", era considerado figura expressiva. Conhecia "como ninguém", segundo ele, as colocações e as pessoas residentes no PAE Cachoeira (Luiz Targino de Oliveira, 2011).

Dercy Teles de Carvalho Cunha, diferentemente de Targino, informou ter nascido em Xapuri, no seringal Boa Vista, colocaçáo Pimenteira. Quando foi procurada pela primeira vez, residia na cidade, mas informou que possuía uma colocaçáo na Resex Chico Mendes, onde "permanecia por alguns períodos do ano". De mesma forma que Targino, destacou ter participado das lutas dos seringueiros contra a expropriação das terras. Disse, ainda, ter sido uma das pioneiras a se destacar no "movimento" - primeira mulher a ocupar a presidência do STTR de Xapuri (Dercy Perez de Carvalho Cunha, 2011).

Semelhante ao que observou Gois (2020), quando coletou narrativas de agricultores do oeste do Rio Grande do Norte, Dercy e Targino trouxeram à tona em suas falas alguns temas específicos. Talvez por acharem que seria aquilo que o pesquisador queria ouvir, ou por estar ainda latente em suas memórias algum sentimento de revolta, relacionado com as lutas que travaram durante o "movimento" contra a expropriação dos territórios.

O grupo de colaboradores seringueiros, portanto, foi constituído (a partir das entrevistas "ponto zero") por residentes em duas localidades significativas: o Projeto de Assentamento Agroextrativista Cachoeira (PAE Cachoeira ou PAE Chico Mendes) ${ }^{5}$

5 O PAE Cachoeira, oficialmente conhecido como PAE Chico Mendes, foi legalizado pela Portaria INCRA/ SR-14/AC n 158 , de 8 de março de 1989, como Projeto de Assentamento Extrativista Chico Mendes. Porém, a portaria do INCRA nº 286 de 23 de outubro de 1996 resolve criar, em substituição à modalidade de Projeto de Assentamento Extrativista, a modalidade de Projeto de Assentamento Agroextrativista. 
e a Reserva Extrativista Chico Mendes. No caso da reserva, a qual engloba outros municípios, coletaram-se histórias de vida somente de moradores residentes em colocaçôes localizadas dentro dos limites do município de Xapuri (AC).

Sobre a Resex Chico Mendes, vale destacar que é a maior da Amazônia, com um total de 976.570 hectares. É basicamente formada por antigos seringais. Dentro de seus limites (localizados entre os municípios acreanos de Assis Brasil, Senador Guiomard, Xapuri, Brasiléia, Epitaciolândia, Sena Madureira e Capixaba) viviam, no início dos anos 2000, aproximadamente 9.000 pessoas distribuídas em 1.100 colocaçôes (Rêgo; Costa Filho; Braga, 1996).

$\mathrm{Na}$ "rede" Resex, coletaram-se 12 relatos. Foram ouvidos seringueiros, 3 mulheres e 9 homens, que residiam em localidades próximas da cidade, em distâncias médias e em distâncias longas (no "fundo da reserva"), onde existia luz elétrica e onde a energia ainda não havia chegado.

No caso do PAE Cachoeira ("rede" 2), Stone-Jovicich et al. (2007) informam que no ano de 2000 existiam 87 famílias "assentadas". Essa área corresponde a 24.898,20 hectares, seu perímetro é de 109.039,07 metros e se localiza no município de Xapuri (AC), distante $218 \mathrm{~km}$ da capital Rio Branco. $\mathrm{O}$ acesso se dá pela BR-317, na altura do km 143, lado esquerdo, sentido Rio Branco - Brasileia, através do "Ramal do Cachoeira”. Da BR-317 até a sede da associação dos moradores desse PAE, são 17 $\mathrm{km}$. A sede da associação fica localizada na colocaçáo denominada Fazendinha (StoneJovicich et al., 2007).

De acordo com informaçóes da Superintendência Estadual do Instituto Nacional de Colonização e Reforma Agrária (Incra), existiam em 2011 cerca de 87 colocaçóes no PAE Cachoeira. Se for considerada a média de indivíduos por família residente na zona rural do estado do Acre, conforme dados do Instituto Brasileiro de Geografia e Estatística (IBGE), tem-se uma estimativa para a população total de 390 habitantes.

Maria Luciana Gomes Verçosa, seringueira que ajudou na construção da pesquisa, informou que no ano de 2012 residiam no PAE Cachoeira 85 famílias. Desse total, coletaram-se os relatos de $11,76 \%$ de seus chefes, ou seja, 10 seringueiros ( 5 mulheres e 5 homens - mais velho 86 anos e mais novo 27 anos).

Vale assinalar que o "Cachoeira", cujo nome se referia a um posto de troca no seringal, foi um seringal importante na regiáo de Xapuri (AC) durante o boom da borracha.

[...] Durante os anos de 1980 o Cachoeira presenciou atos de violência e disputas pelo direito a terra. Em 1988, o fazendeiro pecuarista Darly Alves tentou desmatar e queimar uma parte das florestas de Cachoeira. Na tentativa de impedi-lo, os seringueiros, com a ajuda de Chico Mendes, mobilizaram e realizaram um empate em abril daquele ano, impedindo os homens de Darly de entrarem no seringal. Um segundo empate logo se seguiu quando Darly tentou desmatar parte do Equador, um seringal vizinho. Em consequência desses confrontos, dois seringueiros foram seriamente feridos pelo filho de Darly, Olaci Alves. Em junho de 1988, o líder 
sindicalista Ivair Higino foi assassinado, supostamente por um pistoleiro de Darly. Logo depois, em Dezembro de 1988, Olaci assassinou Chico Mendes. Em resposta, à situação de violência crescente, em 1989, o governo (INCRA) desapropriou a área do seringal Cachoeira e o transformou em um PAE. (Stone-Jovicich et al., 2007, p. 9).

A coleta dos relatos foi realizada com total consentimento dos seringueiros. Com nenhum deles adotou-se a estratégia de utilizar um questionário com perguntas. Isso porque o foco da pesquisa sempre esteve na subjetividade e nas experiências de vida dos que decidiram colaborar e construir conhecimentos através do trabalho.

Durante as gravaçóes (imagem e voz), procurou-se sempre prestar atenção nos discursos, nos silêncios, nos olhares e nas alteraçôes da paisagem, por acreditar que o pesquisador precisa visualizar o lugar para poder entender o que está sendo dito. Entretanto, como o interesse centrava-se principalmente no modo de vida, isso supunha perguntar ou orientar os participantes a falarem sobre as várias dimensóes do vivido. Ou seja, o lugar, o trabalho, os desejos, as dificuldades, o medo, as alegrias, os sonhos, o que sempre era feito antes de ligar os equipamentos de gravaçáo.

Nas conversas prévias os seringueiros eram informados sobre coisas de interesse. Mas procurava-se deixar que escolhessem livremente o que dizer. Assim, eles e elas estariam dando as prioridades que diziam respeito às suas próprias vidas e náo às hipóteses da pesquisa.

Mas nem tudo aconteceu como planejado. Mesmo com as orientaçóes, quando o microfone e a filmadora eram ligados, muitos ficavam tímidos e não falavam. Ficavam aguardando perguntas. Algumas vezes até solicitavam perguntas ("O que o senhor gostaria de saber?”). Alguns começavam a falar e logo finalizavam. Entáo, a estratégia com alguns foi estabelecer pequenos diálogos com vistas à obtençấo dos relatos. Por isso, foram realizadas perguntas sobre o viver na floresta. Inclusive, esse procedimento os motivava a falar com mais naturalidade. Em poucas situaçôes sentiu-se a necessidade de aprofundar algumas questóes apresentadas com indagaçôes.

Apesar da orientação inicial, os seringueiros sempre começavam por onde queriam, paravam também quando queriam e tiveram total liberdade durante o relato de interromper, silenciar, etc. A proposta foi ouvi-los verdadeiramente, o que difere de escutar. Fundamentalmente, o respeito foi mantido como princípio, isto é, respeito às ideias e opinióes divergentes. No final, foi transcrito o diálogo. Registrou-se pela escrita o modo como cada um deles pretendeu se deixar ver.

No processo de passagem do oral para o escrito, incluíram-se variaçóes linguísticas, repetiçóes, gírias, etc. Trabalho demorado, entretanto de grandes aprendizados. Após essa etapa, centrou-se esforço no sentido de dar à entrevista um caráter de texto fluído, visando favorecer a leitura. Nesse momento, adaptaçóes na linguagem foram realizadas, mas com o devido cuidado para não eliminar a cultura. Por isso, foram mantidas expressóes como "varadouro", "estrada de seringa", "beiço do ramal", etc., o que se 
passou a ter, entáo, foram textos abertos para múltiplas interpretaçóes. Em seguida, realizou-se a "transcriação", que consiste na fase final da construção do texto, até a devolução.

Para Castro Barbosa (2009) o processo que compreende todo o trabalho, todos os procedimentos, desde o projeto até a construçáo das leituras é denominado "transcriaçáa". Segundo essa autora, a "transcriaçáo" corresponde em transpor em texto escrito o que foi dito verbalmente, mas náo apenas o que foi dito palavra por palavra. $\mathrm{Na}$ "transcriaçáo" é preciso incluir o significado dos gestos, das lágrimas e o sentido que o narrador desejou passar em determinadas frases ou reticências, ou seja, transcriar teatralizando o que foi dito.

A "transcriação" traz em seu bojo três fundamentos: a colaboração, a mediação e a devolução (Meihy; Holanda, 2007). Por "colaboraçáa", entende-se a relaçáo estabelecida entre o pesquisador e o interlocutor, na qual o segundo age em colaboraçáo ao entrevistador. Mais que prestar informaçóes, ele acompanha o processo de formataçáo da pesquisa. Assim, o pesquisador assume o papel de mediador, possibilitando condiçóes favoráveis à narração, estimulando o diálogo com perguntas abertas e anotando informaçôes relevantes. O trabalho de colaboração é visto como coautoria, mas tendo o pesquisador as responsabilidades jurídicas sobre o projeto. $\mathrm{O}$ produto desse trabalho é a "devolução", o retorno do material produzido para as pessoas ou grupos de participantes, fazendo com que a experiência da história oral atravesse a academia em direção à coletividade, garantindo seu caráter público.

Para Santhiago, o ato de transcriar:

[...] é quando o oralista interfere efetivamente nas entrevistas, confeccionando o documento escrito em três passos: 1) transcrição absoluta da entrevista, com o registro completo de ruídos, repetiçóes e vícios de linguagem; 2) textualização, que suprime elementos desnecessários e incorpora as perguntas à fala do entrevistado, produzindo um texto unissonante; e 3) a transcriação, que recria plenamente o texto.... Lançando mão de recursos literários, devolve a ele o que as palavras meramente transcritas não dão conta de mostrar, como entonações, expressóes irônicas e de duplo sentido; evidencia eventos significativos para a compreensão da entrevista, como o choro ou o riso; facilita a recepção do documento pelo público leitor, articulando blocos temáticos e padronizando variaçóes linguísticas. Nesse momento, a interferência do oralista é clara, explicitada e assumida. Depois disso, o depoente recebe seu texto trabalhado, podendo indicar a necessidade de refacção ou exclusão de partes dele. Reconhecendo-se no documento, autoriza seu uso público, assumindo-se como alguém que efetivamente colaborou para o trabalho de um autor, o oralista. (Santhiago, 2008, p. 41).

O retorno aos seringais foi iniciado em 15 de dezembro de 2012 (para devolução dos relatos e obtenção de suas autorizaçóes para o uso), processo que se estendeu até 
dezembro de 2013. Nesses encontros, percebeu-se que a ideia do retorno do texto para cada um dos seringueiros se parece com o próprio trabalho realizado por eles. Da mesma forma que percebeu Nilson Santos, ou seja:

O interlocutor, por vezes, age como o próprio seringueiro. O texto a ser transcriado é a seringueira, e a faca afiada para não estragar a casca nem estragar as fibras da madeira vai desenhando cada traço em busca do leite, retirando as camadas de casca morta e musgo que se acumulam, desbasta, fere para dar vazão ao fluxo de leite, não para exaurir completamente, esfola para provocar o surgimento da densa seiva, interfere na árvore para retirar dela sua fortuna. Não é possível conseguir o leite da seringueira sem toca-la, sem desrespeita-la, sem irrita-la, sem incomoda-la, não é deixando intocada que se obtém sua riqueza, mas é cravando com precisão a faca na sua casca que ela libera o leite. Náo se contenta somente com uma ideia, com a abundância do leite por um fabrico, quer preservar a vida da arvore e a riqueza do narrador, garantindo-lhe presença e vida em abundância. $\mathrm{O}$ limite dessa intervenção deve ser buscado na seringueira, observando se é nova, velha, se saudável. A transcriação cessa quando o texto consegue ser compreensivo como a voz do narrador, mantidas as suas escolhas e enredos por reconhecer o leite, o fluido singular da vida no texto. (Santos, 2002, p. 47).

\section{Considerações finais: alguns resultados da pesquisa}

A análise crítica das fontes evidenciou que as mudanças mais significativas nos modos de viver na regiáo pesquisada vincularam-se diretamente com as políticas públicas implementadas por um grupo político que assumiu o Governo do Acre em 1999 e se auto intitulou "Governo da Floresta". Mudanças provocadas principalmente pelas açóes de uma proposta de política alicerçada em postulados desenvolvimentistas, como no tempo dos militares, mas com uma nova roupagem.

Observa-se que o desenvolvimento no Acre a partir de 1999 passou a ser apresentado, pelo menos no discurso, com um adjetivo: "sustentável". Inclusive, o Governo Estadual criou o neologismo "florestania" para tentar dar conta de tudo que acontecia, neologismo que virou uma espécie de mantra no discurso governamental que usou e abusou do nome e da imagem de Chico Mendes.

A proposta de "desenvolvimento sustentável" do Governo do Acre prometia reverter o processo de crise estabelecida na floresta (desmatamentos, baixos rendimentos das famílias seringueiras, etc.). Isso seria feito através de açôes que visavam modernizar tecnicamente, por dentro, o extrativismo tradicional de borracha e castanha - teóricos da Universidade Federal do Acre (UFAC) ligados ao Governo conceituaram essas 
práticas como "neoextrativismo". Foi nesse contexto que o Governo adotou e passou a internalizar nos coraçóes e mentes dos acreanos que a floresta deveria ser utilizada de "forma racional e inteligente". Se não fosse assim, dizia o Governo, a população que ali habitava correria um alto risco de perder a floresta (discurso construído pelos financiadores externos da política). ${ }^{6}$

Foi assim que se priorizou a exploração "sustentável” de madeira em áreas protegidas. De acordo com os relatos coletados e experiências concretas, a exploração provocou repercussóes fortes na zona rural não somente em Xapuri, como em todo o estado do Acre.

Os seringueiros narraram que a priorização da atividade madeireira impactou fortemente no modo de vida daqueles que aderiram a ela (como em todo tecido social organizativo). A estratégia do manejo provocou divisóes nas representaçóes e movimentos sociais, como também dividiu os sindicatos e os próprios seringueiros. Para uns, o manejo era a legalização dos desmatamentos. Para outros, uma forma de evitar o predomínio da pecuária. A exploração comercial de madeira dividiu inclusive aliados do ambientalismo. Apareceram alguns seringueiros mais privilegiados que outros. Como também apareceram aqueles que, além da venda de madeira, passaram a receber bolsas para difundirem a ideia da venda da madeira.

$\mathrm{Na}$ perspectiva de "modernização" do Governo Estadual, além do manejo madeireiro, outros investimentos foram efetivados na região. Investimentos que impactaram na vida das famílias seringueiras. Merece destaque a implantação de unidades produtivas industriais, como uma fábrica de preservativos denominada Natex e uma indústria para processar madeira "manejada” (indústria de "pisos/tacos"). Investimentos realizados com apoio financeiro (e técnico) de organismos como o Banco mundial/ Banco Internacional para Reconstrução e Desenvolvimento (BIRD), Banco Interamericano de Desenvolvimento (BID), Banco Nacional de Desenvolvimento Econômico e Social (BNDES) e de grandes Organizações Não Governamentais (ONGs) ambientalistas (no caso das ONGs, menos financiamento e mais apoio e assistência técnica). Segundo os relatos coletados, os investimentos na área pesquisada provocaram importantes mudanças. Algumas consideradas muito "boas", outras "nem tanto".

Os seringueiros relataram que os "varadouros" - caminhos na mata que ligavam uma colocação a outra - transformaram-se em ramais trafegáveis, encurtando as distâncias (caminhadas de 12 horas na mata foram substituídas por 2 horas, de moto). Falaram sobre a chegada da energia elétrica nas residências e com ela a televisão com seus milhares de estímulos que impactaram nos gostos e nas práticas cotidianas. Narraram também sobre melhorias na educação e saúde.

Novos desejos foram criados e o sonho de morar na cidade foi potencializado

6 Banco Mundial/Banco Internacional para Reconstrução e Desenvolvimento (BIRD), Banco Interamericano de Desenvolvimento (BID), etc. 
(notadamente entre os mais jovens).

Hoje já tem um transporte melhor, a gente já anda de carro aqui para todo canto. Anda de moto, de bicicleta, conforme puder. Se precisa de alguma coisa tem como ir na rua comprar. Antigamente, a gente criava uma família socada nessas matas e não conhecia nem rua, porque não tinha nem como a gente sair. (Cecília Teixeira do Nascimento, 2012).

Na busca por alternativas de "fazer mais dinheiro" (afinal, com o ramal trafegável, possuir uma moto, ou mesmo um carro, passava a ser considerado fundamental). Além do manejo madeireiro os seringueiros passaram a aumentar as criaçóes de gado (atividade proibida no PAE e na Resex) e, ainda, começaram a praticar com mais intensidade a agricultura comercial.

Muitos seringueiros relataram que suas famílias até conseguiam aumentar os rendimentos através da criaçáo de gado e do manejo madeireiro. Mesmo assim, constatou-se que os ganhos não se mostravam suficientes. Talvez por isso muitos recebessem complementos de renda através dos programas sociais como Bolsa Família e/ou Bolsa Verde.

Especificamente no caso do manejo de madeira, ao mesmo tempo em que gerava rendimentos no curto prazo para alguns, também "espantava a caça", "destruía as nascentes" e "danificava os ramais", fatos que provocavam temores dos seringueiros com relaçáo ao futuro da floresta e a seus próprios futuros (inclusive nas áreas de floresta onde a atividade ainda náo havia chegado no momento da pesquisa). Entretanto, mesmo temerosos, desconfiados e sabedores sobre quem realmente ganhava com a atividade (na época um única madeireira), como também conscientes de que Chico Mendes dificilmente concordaria com esse tipo de exploração, muitos aceitavam vender a madeira de suas colocaçóes. Nesse processo, a pesquisa evidenciou outra questáo importante: a fragilização política a que estavam sendo submetidos.

O fragmento abaixo, do relato da seringueira Cecília Teixeira do Nascimento, configura o discurso ideológico e a subjugaçáo das pessoas aos discursos dominantes:

Como é a vida de hoje? A vida de hoje é por umas partes boa e por outras não [...] Agora é ruim porque tudo que a gente faz tem que ter uma pessoa mais do que a gente. Para a gente se colocar, para a gente arrumar um lugar para a gente fazer qualquer coisa. Tudo é preciso de outra pessoa tá no meio, né? Antigamente não era assim, antigamente você morava aqui e dizia: eu vou abrir um lugarzinho ali, eu vou fazer em outro lugar. Aí já metia o terçado, abria, e fazia um paiolzinho, uma choupana, ia para debaixo. Ou então fazia uma casinha. A vida era assim. Agora não, tudo tem que ter uma reunião, tem que ter uma palestra, tem que ter um negócio. Por isso eu não acho bom não, acho ruim. (Cecília Teixeira do Nascimento, 2012, grifos do autor).

As narrativas denunciaram um constante bombardeio de informaçóes sobre a 
importância do manejo de madeira levadas por técnicos governamentais e ONGs que se diziam apoiadoras das lutas dos seringueiros. Os relatos tornaram claro que muitos seringueiros, mesmos receosos com relação à extração de madeira em suas colocaçóes, aceitavam a ideia, pois percebiam que a atividade madeireira constituía-se em estratégia importante do governo que tinham ajudado a eleger. $\mathrm{O}$ mesmo governo que, desde o princípio, apresentava-se como sucessor das ideias de Chico Mendes (transformado em herói da pátria).

Entre os moradores das colocaçóes mais afastadas ("fundo da reserva"), como também entre as famílias que não estavam sob a área de influência da Natex (não vendiam látex), o estudo permitiu compreender que a situação era bastante complicada. Os seringueiros dessas regióes não estavam conseguindo "fazer o básico", principalmente realizando o que sempre fizeram desde que se tornaram seringueiros (extrair produtos da floresta). ${ }^{7}$

Os relatos evidenciaram também que a partir do ano de 2007 aconteceu uma mudança importante nas açôes do Governo na regiâo, exatamente quando a "florestania" assimila uma nova proposta dos financiadores externos que, agora, orientava para a precificaçáo dos bens naturais (onde as açóes antrópicas precisariam ser minimizadas). Essa mudança provocou rumos novos na política pública acreana, causando impactos significativos na vida da/na floresta. As atividades que os seringueiros exerciam, há anos, passaram a ser controladas e/ou suspensas. Nesse movimento, muitos passaram a "sofrer represálias". A exigência, após 2007, era que se tornassem "guardiōes da floresta".

As narrativas deixaram claro que os mais jovens estavam indo embora da floresta, embebecidos com "desejos de cidade" e sonhando com prováveis oportunidades que poderiam ter fora da mata. Os mais velhos (acima dos 30 anos), por estarem acostumados e saberem que não teriam muitas perspectivas vivendo na zona urbana, narravam que ainda desejavam ficar. Entretanto, como morrerão em um prazo não muito longo, no futuro não estarão mais na floresta. Sendo assim, foi possível inferir que os seringueiros poderáo desaparecer enquanto categoria social, deixando o território limpo para uma provável exploração dos recursos naturais. Um risco que mereceria, no mínimo, ser considerado pela sociedade.

Portanto, os seringueiros de Xapuri (AC) que resistiram bravamente nas matas após os ciclos e crises da borracha, que sobreviveram ao movimento de expropriaçáo provocado pela expansão da fronteira agrícola promovida pelos militares nos anos de 1970 e 1980 em termos de uma perspectiva modernizante, no tempo histórico estudado caminhavam, à época da pesquisa, para a extinçâo enquanto categoria social.

\footnotetext{
"[...] a nova produção discursiva do desenvolvimento sustentável em contraste com o lema do "clássico" "use-o ou perca-o", passou a ser a de agregar valor financeiro aos recursos e processos naturais ameaçados ao se comprometer em os manter intocados, ou seja, não usá-los. Dessa forma, os moradores das florestas passam a ser descritos como "guardiões da floresta" e, de fato, privados de seu direito de livre interação com os elementos da natureza, passam a preencher no cenário da Economia Verde a função de imóveis "espantalhos culturais", tendo a única atribuição de vigilância para que os processos de acumulação de capital, a partir de seu território, ocorram imperturbados” (Schmidlehner, 2013, p. 31).
} 


\section{Referências}

ALBUQUERQUE, Gerson Rodrigues de. Trabalhadores do Muru, o rio das cigarras. Rio Branco: Edufac, 2005.

BARBOSA, Xenia de Castro. Experiências de Moradia: história oral de vida familiar. Dissertação (Mestrado em História Social) - USP, São Paulo, SP, 2009.

BENJAMIN, Walter. O Narrador. In: BENJAMIN, Walter. Magia e técnica, arte e política: ensaios sobre literatura e história da cultura. São Paulo, Brasiliense, 1985. (Obras Escolhidas, 1).

FÁVERO, Douglas Gonsalves.; MORAIS, Sérgio Paulo. História Oral e a juventude trabalhadora na periferia: limites, pressôes e expectativas. História Oral, v. 23, n. 2, p. 155-177, jul./dez. 2020.

GOIS, Sarah Campelo Cruz. Os "projetos de morte" nas narrativas de agricultores do oeste do Rio Grande do Norte. História Oral, v. 23, n. 2, p. 135-153, jul./dez. 2020.

LIMA, Fabiana Moreira; SILVA, Henrique Salmazo da. Compreensões da velhice satisfatória em mulheres idosas do Distrito Federal: aspectos da história de vida e as influências da classe social. História Oral, v. 24, n. 1, p. 127-148, jan./jun. 2021.

LIMA JÚNIOR. Josivaldo Bentes. O guardião do pássaro da noite: memórias de luta e solidariedade no Mocambo do Arari, Parintins (AM). História Oral, v. 24, n. 1, p. 65-85, jan./ jun. 2021.

MARIANO, Agnes Francine de Carvalho. "A memória é a matéria essencial das entrevistas": Entrevista com José Carlos Sebe Bom Meihy. Lumina, Juiz de Fora, v. 14, n. 3, p. 213-226, set./ dez. 2020.

MARTINELLO, Pedro. A "batalha da borracha" na Segunda Guerra Mundial e suas consequências para o Vale Amazônico. Cadernos da UFAC, Rio Branco, n. 1, Série “C”, 1988.

MARTINS, José de Souza. A reprodução do capital na frente pioneira e o renascimento da escravidão no Brasil. Tempo Social, São Paulo, v. 6, p. 1-2, p. 1-25, 1994.

MARTINS, José de Souza. O tempo da fronteira. Retorno à controvérsia sobre o tempo histórico da frente de expansão e da frente pioneira. Tempo Social, São Paulo, v. 8, n. 1, p. 25-70, 1996.

MEIHY, José Carlos Sebe Bom. Manual de História Oral. São Paulo: Ediçóes Loyola, 1996.

MEIHY, José Carlos Sebe Bom; HOLANDA Fabíola. História Oral: como fazer, como pensar. São Paulo: Contexto, 2007.

RÊGO, José Fernandes do; COSTA FILHO, Orlando Sabino da; BRAGA, Robinson Antônio da Rocha (Coord.). Análise Econômica de Sistemas de Produção Familiar no Vale do Acre - 1996/1997. Rio Branco: UFAC/Departamento de Economia, 1996.

SANTOS, Nilson. Seringueiros da Amazônia: sobreviventes da fartura. Tese (Doutorado em História Social) - São Paulo, USP, SP, 2002.

SANTHIAGO, Ricardo. Da fonte oral à história oral: debates sobre legitimidade. Saeculum, João Pessoa, n. 18, p. 33-46, jan./ jun. 2008.

STONE-JOVICICH, Samantha et al. Acompanhamento para o manejo florestal comunitário no 
projeto Cachoeira, Acre, Amazônia, Brasil. Bogor: Cifor; Belém: Imazon, 2007.

SCHMIDLEHNER, Michael F. Os desdobramentos do capitalismo de desastre no Acre - "a adicionalidade do medo". Contra Corrente, Belém, n. 5, p. 29-32, set. 2013.

THOMPSON, Paul. A voz do passado: história oral. São Paulo: Paz e Terra, 1992.

\section{Fontes orais}

CUNHA, Dercy Teles de Carvalho [57 anos]. [out. 2011]. Entrevistador: Carlos Estevão Ferreira Castelo. Xapuri, AC, 15 out. 2011.

OLIVEIRA, Luiz Targino de [78 anos]. [out. 2011]. Entrevistador: Carlos Estevão Ferreira Castelo. Xapuri, AC, 7 out. 2011.

NASCIMENTO, Cecília Teixeira do [86 anos]. [maio 2012]. Entrevistador: Carlos Estevão Ferreira Castelo. Xapuri, AC, 5 maio 2012.

Recebido em 22/01/2021.

Versão final reapresentada em 03/05/2021.

Aprovado em 08/08/2021.

Fonte de financiamento: nada a declarar.

Conflitos de interesse: nada a declarar. 